\title{
Congenital Nevus Araneus
}

National Cancer Institute

\section{Source}

National Cancer Institute. Congenital Nevus Araneus. NCI Thesaurus. Code C4806.

A type of telangiectasia, comprised of a central red spot with radiating, red extensions, that is present at the time of birth. 